\title{
Aberrant microRNA-137 promoter methylation is associated with lymph node metastasis and poor clinical outcomes in non-small cell lung cancer
}

\author{
LINGFENG MIN $^{1 *}$, FANG WANG $^{1 *}$, SUWEI HU ${ }^{3 *}$, YONG CHEN $^{2}$, \\ JUNJUN YANG ${ }^{1}$, SUDONG LIANG ${ }^{4}$ and XINGXIANG XU ${ }^{1}$
}

\author{
Departments of ${ }^{1}$ Respiratory Medicine and ${ }^{2}$ Medical Oncology, Subei People's Hospital, \\ Clinical Medical College of Yangzhou University, Yangzhou, Jiangsu 225001; ${ }^{3}$ Medical Genetic Center, \\ The Affiliated Hospital of Yangzhou University, Yangzhou, Jiangsu 225002; ${ }^{4}$ Department of Urology, \\ Taizhou People's Hospital, Taizhou, Jiangsu 225300, P.R. China
}

Received October 18, 2016; Accepted January 12, 2018

DOI: $10.3892 / \mathrm{ol} .2018 .8273$

\begin{abstract}
MicroRNA-137 (miR-137) functions as a tumor suppressor and is silenced by aberrant promoter methylation. Previous studies have demonstrated that miR-137 is downregulated in lung cancer. The purpose of the present study was to investigate miR-137 promoter methylation and to assess its prognostic value in non-small cell lung cancer (NSCLC). The expression of miR-137 was analyzed inhuman lung cancer A549 and H1299 cells and normal bronchial epithelial BEAS-2B cells, 10 paired formalin-fixed paraffin-embedded lung cancer and normal tissue samples, and 56 archived paraffin-embedded lung cancer tissues. Quantitative methylation-specific polymerase chain reaction analysis was used to assess the miR-137 methylation status. The associations between miR-137 promoter methylation and the clinicopathological features and prognosis of patients with NSCLC $(n=56)$ were analyzed using analysis of variance. miR-137 was markedly downregulated in lung cancer cells and lung cancer tissue specimens compared with expression in BEAS-2B cells and matched adjacent normal lung tissues. A significant negative correlation between miR-137 expression and miR-137 promoter methylation was observed in human lung cancer tissues $(\mathrm{r}=-0.343 ; \mathrm{P}=0.01)$. Smoking, lymph node metastasis and advanced clinical stage were associated with significantly lower expression of miR-137 in variance analysis. High levels
\end{abstract}

Correspondence to: Professor Xingxiang $\mathrm{Xu}$, Department of Respiratory Medicine, Subei People's Hospital, Clinical Medical College of Yangzhou University, 98 Nantong West Road, Yangzhou, Jiangsu 225001, P.R. China

E-mail: xuxx63@sina.com

*Contributed equally

Key words: clinicopathological characteristics, microRNA-137, non-small cell lung cancer, prognostic value, promoter methylation of miR-137 promoter methylation were associated with a significantly poorer disease-free survival rate $(\mathrm{P}=0.034)$, but were not associated with overall survival, in Kaplan-Meier analysis and univariate analysis. In conclusion, the results of the present study indicated that miR-137 is downregulated and that its promoter is aberrantly methylated in lung cancer, and that high levels of miR-137 promoter methylation may have prognostic value for poor disease-free survival.

\section{Introduction}

Lung cancer is the most frequently diagnosed malignancy and the leading cause of cancer-associated mortality worldwide (1). Non-small cell lung cancer (NSCLC) accounts for $85-90 \%$ of all lung cancer cases (2). Patients diagnosed with symptomatic lung cancer have a poor prognosis, with an overall 5-year survival rate of $16 \%$ in the United States (3).

Lung carcinogenesis is a multistep process associated with the activation of oncogenes and the inactivation of tumor-suppressing genes (4). However, the molecular mechanisms underlying the progression of NSCLC remain poorly understood. Therefore, there is an urgent requirement for further investigation of the mechanisms that lead to the development and progression of lung cancer in order to identify novel biomarkers and therapeutic targets.

MicroRNAs (miRNAs) are small, non-coding RNAs 22 nucleotides in length that regulate gene expression by either degradation or repression of mRNA translation (5). MicroRNAs serve essential roles in a variety of biological processes, including cell death, differentiation, proliferation and metabolism $(5,6)$. Altered miRNA expression occurs in numerous types of human cancer (7) and is associated with the initiation and progression of cancer (8). The expression of miRNAs may be controlled through epigenetic mechanisms, with $\sim 10 \%$ of miRNAs being regulated by DNA methylation (9).

MicroRNA-137 (miR-137) is located on human chromosome $1 \mathrm{p} 21.3$ and is embedded in a CpG island $(10,11)$. miR-137 is frequently downregulated in several types of cancer, 
including colorectal cancer, gastric cancer, glioblastoma and NSCLC (12-16). Previous studies have suggested that miR-137 silencing may be the result of hypermethylation of the miR-137 gene promoter $(11,15,16)$. miR-137 promoter methylation is associated with poor prognosis in certain types of cancer, including gastric cancer (17) and squamous cell carcinoma of the head and neck (18). A previous study by Kang et al demonstrated that the level of miR-137 promoter methylation was significantly higher in lung tumors than in the adjacent non-tumor tissues (19). However, the aforementioned study did not assess whether miR-137 promoter methylation has prognostic value for recurrence or overall survival in lung cancer (19).

The principal aim of the present study was to evaluate whether methylation of the miR-137 promoter represents a prognostic biomarker for overall and disease-free survival in NSCLC. The overall objective of the present study was to provide an experimental and theoretical basis for further study of the associations between miR-137 promoter methylation and prognosis in NSCLC.

\section{Materials and methods}

Ethical approval. The present study was approved by the Ethics Committee of Subei People's Hospital (Yangzhou, China) and written informed consent was obtained from all participants.

Study population. A total of 10 pairs of $4 \%$ formalin-fixed for $24 \mathrm{~h}$ at room temperature, paraffin-embedded (FFPE) NSCLC tissues and corresponding matched non-tumor lung tissues were collected (from 4 patients with squamous cell carcinoma and 6 patients with adenocarcinoma) between May 2012 and October 2012, at Subei People's Hospital. A further 56 FFPE NSCLC tissues (from 31 patients with squamous cell carcinoma and 25 patients with adenocarcinoma) were obtained between February 2008 and December 2009. All tissue samples were collected prior to treatment with chemoradiotherapy. Each sample was confirmed by histopathological evaluation using hematoxylin and eosin staining. Clinical data were recorded at the time of resection and patients were prospectively followed-up to ascertain vital status (the last follow-up date was April 30, 2012).

Cell culture. Human lung cancer A549 and H1299 cells and normal bronchial epithelial BEAS-2B cells were purchased from the Cell Resource Center, Shanghai Institute of Biochemistry, China. (http://www.sibcb.ac.cn/) BEAS-2B cells were derived by transforming human bronchial epithelial cells with an adenovirus 12-simian virus 40 construct, as previously described (20). The cell lines were maintained in RPMI-1640 medium supplemented with $10 \%$ fetal bovine serum (both from Wisent, Inc., St. Bruno, QC, Canada) at $37^{\circ} \mathrm{C}$ in a humidified air atmosphere containing $5 \%$ carbon dioxide.

Treatment with 5-aza-2'-deoxycytidine. A549 and H1299 cells were seeded onto 24-well plates on day 0 , exposed to the DNA methylation inhibitor 5-aza-2'-deoxycytidine (5-aza-dC; Sigma-Aldrich; Merck KGaA, Darmstadt, Germany) at a final concentration of $5 \mu \mathrm{mol} / 1$ between day 1 and day 3 at $37^{\circ} \mathrm{C}$ in a humidified air atmosphere containing $5 \% \mathrm{CO}_{2}$ and were harvested under Trypsin-EDTA digestion harvested for RT-qPCR analysis of miR-137 expression on day 4.

RNA isolation. Total RNA was extracted from cultured cells using TRIzol reagent (Invitrogen; Thermo Fisher Scientific, Inc., Waltham, MA, USA). Total tissue RNA was extracted from FFPE tissue sections using the miRNeasy FFPE kit (Qiagen, Inc., Valencia, CA, USA) according to the manufacturer's protocol. Paraffin was removed from freshly cut FFPE tissue sections each up to $10-\mu \mathrm{m}$ thick using deparaffinization solution using the miRNeasy FFPE kit (Qiagen, Inc.), and samples under went protease digestion at room temperature to release RNA from the sections, then short incubation (at $56^{\circ} \mathrm{C}$ for $15 \mathrm{~min}$, then at $80^{\circ} \mathrm{C}$ for $15 \mathrm{~min}$ ) to reverse formalin cross-linking of the released nucleic acids and DNase digestion to remove DNA. Total RNA (including miRNAs) was dissolved in $20 \mu 1$ RNase-free water. RNA concentrations were measured using a NanoDrop-1000 (Thermo Fisher Scientific, Inc.) and RNA integrity was determined by $1.5 \%$ agarose gel electrophoresis.

Reverse transcription-quantitative polymerase chain reaction (RT-qPCR) analysis of miRNA-137 expression. RNA was reverse transcribed using the RevertAid First Strand cDNA kit (Thermo Fisher Scientific, Inc.) according to the manufacture's protocolin combination with a stem-loop primer for miRNA-137U6 small nuclear RNA was used as an internal control to normalize the expression levels of miRNA-137. The primer sequences are presented in Table I. Briefly, $1.0 \mu \mathrm{g}$ total RNA was combined with $4.0 \mu \mathrm{l}$ Ribo Lock RNase inhibitor, $2.0 \mu \mathrm{l} \mathrm{dNTP} \mathrm{mix} \mathrm{(10} \mathrm{mM} \mathrm{each)} \mathrm{and} 1.0 \mu \mathrm{l}$ RevertAid $\mathrm{M}-\mathrm{MuLV}$ reverse transcriptase in a total reaction volume of $20 \mu \mathrm{l}$, which was incubated on an ABI Prism 7900HT Fast Real-Time PCR system (Applied Biosystems; Thermo Fisher Scientific, Inc.) at $25^{\circ} \mathrm{C}$ for $5 \mathrm{~min}, 42^{\circ} \mathrm{C}$ for $60 \mathrm{~min}$ and $70^{\circ} \mathrm{C}$ for $5 \mathrm{~min}$.

RT-qPCR was performed using LightCycler ${ }^{\circledR} 480$ SYBR-Green I Master mix on a LightCycler ${ }^{\circledR} 480$ Real-Time PCR system (both Roche Diagnostics, Basel, Switzerland). Each $10 \mu \mathrm{l}$ PCR mixture contained $1 \mu 1$ 20-fold diluted reverse transcription product, $5 \mu \mathrm{l}$ SYBR-Green Master mix, $2 \mu \mathrm{l}$ RNase-free water, and $1 \mu \mathrm{l}$ forward and reverse primers. The reactions were incubated at $95^{\circ} \mathrm{C}$ for $10 \mathrm{~min}$, followed by 40 cycles of $95^{\circ} \mathrm{C}$ for $15 \mathrm{sec}$ and $65^{\circ} \mathrm{C}$ for $60 \mathrm{sec}$. Relative miRNA-137 expression was calculated using the $2^{-\Delta \Delta \mathrm{Cq}}$ method (21), where $\Delta \mathrm{Cq}$ is the difference in threshold cycles $(\mathrm{Cq})$ for the target and reference $=\mathrm{Cq}(\mathrm{miRNA}-137)-\mathrm{Cq}(\mathrm{U} 6)$. $\mathrm{RT}$ and PCR primers were synthesized by Shanghai Sheng Gong Biology Engineering Technology Service, Ltd. (Shanghai, China).

Analysis of miR-137 promoter lesion and sodium bisulfate conversion. The miR-137 CpG is lands were identified using EMBOSS Software Version 6.3.1 (Institut Pasteur,Paris, France) and EMBOSS (http://gensoft.pasteur.fr/docs/EMBOSS/6.3.1/). Total tissue DNA was extracted from FFPE tissue scrolls using the Qiagen EpiTect Plus FFPE Bisulfite kit (Qiagen, Inc.) according to the manufacturer's protocol. FFPE tissue scrolls were deparaffinized, followed by proteinase digestion and de-cross-linking as aforementioned in RNA isolation 
Table I. Primer sequences.

Primer

Sequence (5'-3')

miRNA reverse transcription primer sequence
miRNA-137
U6 snRNA
qPCR primer sequence
miRNA-137 forward
miRNA-137 reverse
U6 snRNA forward
U6 snRNA reverse
MS-qPCR primer sequence
Methylated alleles forward
Methylated alleles reverse
Unmethylated alleles forward
Unmethylated alleles reverse

TTATTGCTTAAGAATACGCGTAG AAAATATGGAACGCTTCACGAATTTG

CAAGGCTTGTTAACACTGTAAC
TCTGTCAATGTCTGAATAAATG
CTCGCTTCGGCAGCACATATACT
ACGCTTCACGAATTTGCGTGTC

5'-GCGGTAGTAGTAGCGGTAGC-3'

5'-ACCCGTCACCGAAAAAAA-3'

5'-GGTGGTAGTAGTAGTGGTAGT-3'

5'-TACCCATCACCAAAAAAAA-3'

qPCR, quantitative polymerase chain reaction; MS, methylation specific; miRNA, microRNA; snRNA, small nuclear RNA.

paragraph. The DNA bisulfite reaction was then set up and performed using an ABI Prism 7900HT Fast Real-Time PCR system (Applied Biosystems; Thermo Fisher Scientific, Inc.) using the Qiagen EpiTect Plus FFPE Bisulfite kit (Qiagen, Inc.) according to the manufacturer's protocol. Upon completion of the bisulfite conversion, modified DNA was purified and eluted, the DNA concentrations were measured using a NanoDrop-1000 (Thermo Fisher Scientific, Inc.) and the samples were stored at $-20^{\circ} \mathrm{C}$ for further analysis.

Methylation-specific (MS) qPCR. The methylation status of the miR-137 promoter in the FFPE tissue sample was determined by MS-qPCR, as previously described (19). Modified DNA (10 ng) was subjected to PCR amplification on an ABI Prism 7900HT Fast Real-Time PCR system (Applied Biosystems; Thermo Fisher Scientific, Inc.) at $90^{\circ} \mathrm{C}$ for $5 \mathrm{~min}$, followed by 40 cycles of $95^{\circ} \mathrm{C}$ for $15 \mathrm{sec}, 60^{\circ} \mathrm{C}$ for $30 \mathrm{sec}$ and $72^{\circ} \mathrm{C}$ for $15 \mathrm{sec}$, then a $10 \mathrm{~min}$ final extension at $72^{\circ} \mathrm{C}$. The PCR products were diluted 500-fold with water, and $1 \mu \mathrm{l}$ aliquots were subjected to MS-qPCR using a LightCycler ${ }^{\circledR} 480$ SYBR-Green I Master (Roche Diagnostics) at $95^{\circ} \mathrm{C}$ for $10 \mathrm{~min}$, followed by 40 cycles of $95^{\circ} \mathrm{C}$ for $15 \mathrm{sec}$ and $51^{\circ} \mathrm{C}$ for $60 \mathrm{sec}$, calculated with the formula $2^{-\Delta \mathrm{Cq}}[\mathrm{Cq}$ (methylated)- $\mathrm{Cq}$ (unmethylated)] (21), and expressed as a percentages. qPCR primer sequences are listed in Table I.

Statistical analysis. Data were analyzed using the SPSS 18.0 statistical software (SPSS, Inc., Chicago, IL, USA). Values presented as the mean \pm standard deviation and were analyzed using one-way analysis of variance with post hoc analysis by least significant difference (LSD) test. The correlation between miR-137 expression and tissue methylation levels was evaluated using Pearson's correlation analysis. Descriptive statistics were used to compare the demographic and clinicopathological characteristics (sex, age, pathology, smoking, status, tumor size, histologic grade, T category, lymph node metastasis and clinical stage) (22) of the study population stratified by the
miR-137 promoter methylation status, and categorical variables were compared using analysis of variance with post hoc analysis by LSD test. The univariate Kaplan-Meier method was used to estimate disease-free survival and overall survival rates, and survival differences were compared using the log-rank test. In analysis of disease-free and overall survival rates, patients who succumbed prior to recurrence were considered censored at the point of mortality. A multivariable Cox proportional hazards model was used to assess the prognostic value of the level of miR-137 promoter methylation for disease-free and overall survival rates, following adjustment for sex, age, histological grade, $\mathrm{T}$ category, age and smoking status. $\mathrm{P}<0.05$ was considered to indicate a statistically significant difference.

\section{Results}

miR-137 is down regulated in lung cancer cell lines and human tumor tissues. The expression of miR-137 was determined by qRT-PCR (Fig. 1). miR-137 was markedly downregulated in lung cancer A549 and H1299 cells compared with that in normal lung bronchial epithelial BEAS-2B cells (Fig. 1A). In line with the cell line analyses, the expression of miR-137 was significantly downregulated in the 10 FFPE lung cancer tissue specimens compared with that in the paired adjacent normal lung tissues $(\mathrm{P}=0.037$; Fig. $1 \mathrm{~B}$ and $\mathrm{C})$.

Promoter hypermethylation downregulated miR-137 in lung cancer cell lines and human tumor tissues. CpG plot EMBOSS Software version 6.3.1 software (http://gensoft .pasteur.fr/docs/EMBOSS/6.3.1/; Institut Pasteur, Paris, France) identified $2 \mathrm{CpG}$ islands located close to the miR-137 gene (Fig. 1D) and promoter hypermethylation has previously been reported to be responsible for the repression of miR-137 (14). Therefore, miR-137 expression was analyzed in a lung cell line treated with the methyltransferase inhibitor 5-aza-CdR ( $5 \mu \mathrm{mol} / \mathrm{l})$. Untreated control cells expressed lower 

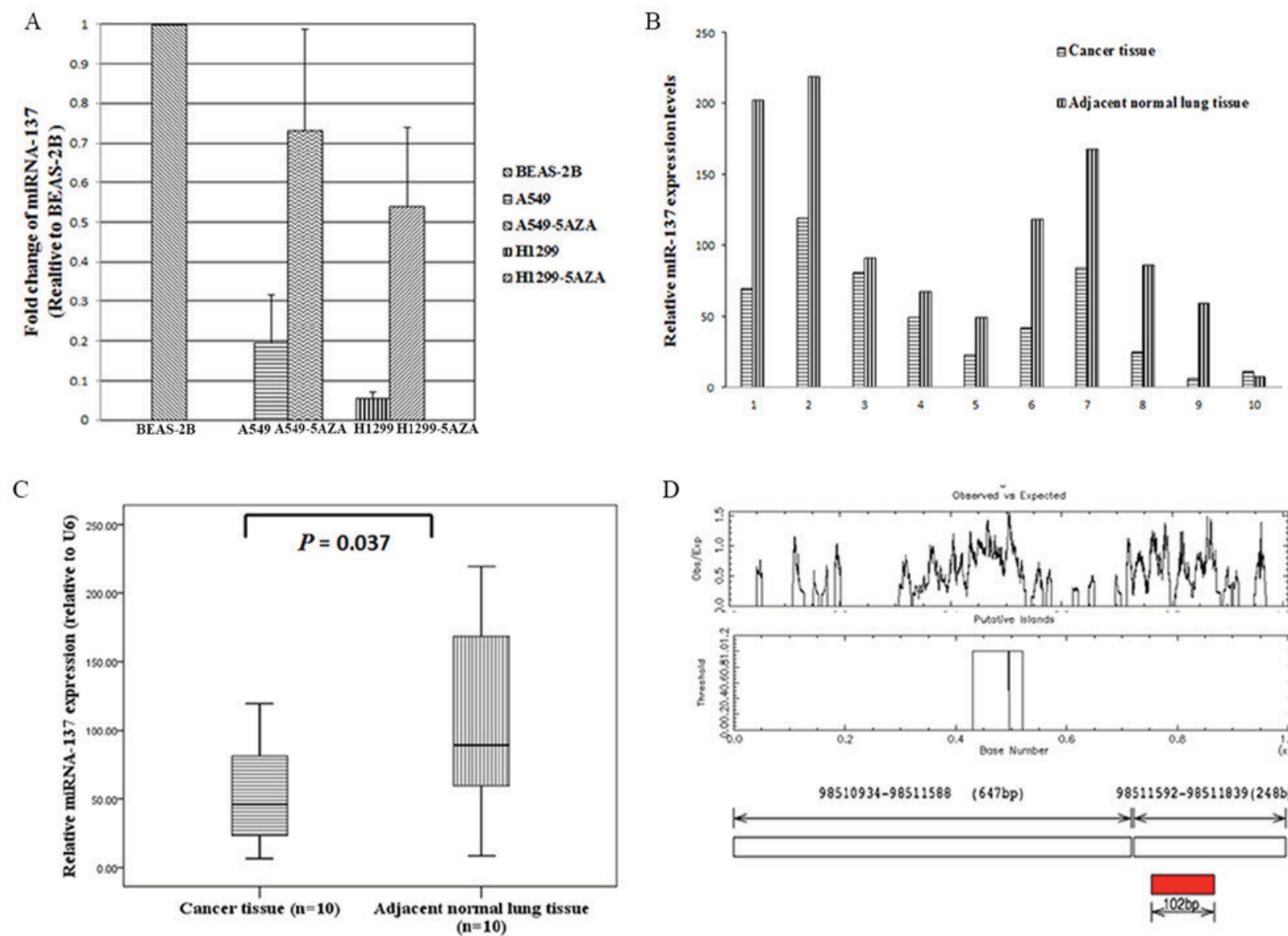

$\mathrm{D}$
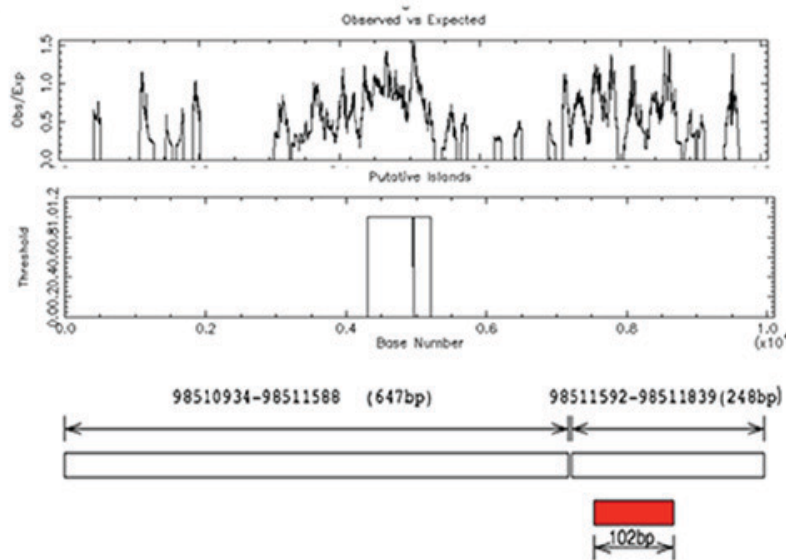

Figure 1. miRNA-137 is downregulated in lung cancer cell lines and clinical specimens. (A) The relative expression of miRNA-137 in A549 and H1299 lung adenocarcinoma cells and BEAS-2B normal bronchial epithelial cells was determined by RT-qPCR assay and normalized to U6. Values a represented as fold-changes relative to BEAS-2B cells. Results are presented as the mean \pm standard deviation of 3 independent experiments. (B) Relative expression of miR-137 in 10 paired lung cancer tissues and the corresponding non-tumor lung tissues was determined by RT-qPCR assay and normalized to U6 with (C) quantification. miRNA, microRNA; RT-qPCR, reverse transcription-quantitative polymerase chain reaction. (D) Illustration of CpG site in miR-137. miRNA, microRNA; RT-qPCR, reverse transcription-quantitative polymerase chain reaction.

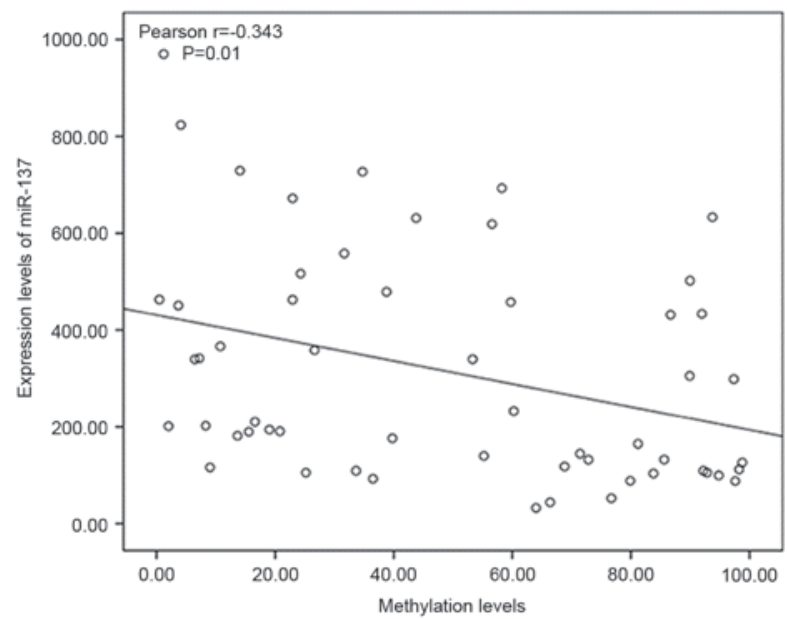

Figure 2. miR-137 promoter methylation is significantly negatively correlated with miR-137 expression in lung cancer tissues $(n=56 ; r=-0.343, P=0.01$; Pearson's correlation). miR, microRNA.

levels of miR-137, whereas 5-aza-CdR-treated cells expressed higher levels of miR-137 (Fig. 1A). The methylation status of the CpG sites was consistent with the levels of miR-137 expressed in the lung cancer cell lines.
Subsequently, miR-137 expression and the promoter methylation status in the 56 FFPE lung cancer tissues were compared using RT-qPCR and MS-qPCR. A significant negative correlation between the expression level of miR-137 and miR-137 promoter methylation was observed in the lung cancer tissues (Pearson's correlation, $r=-0.343, P=0.01$; Fig. 2), suggesting that promoter methylation silences miR-137 in lung cancer.

miR-137 promoter methylation status is associated with lymph node metastasis and advanced clinical stage. To determine whether the miR-137 promoter methylation status is associated with lung cancer, the association between the miR-137 promoter methylation status and the clinicopathological characteristics of lung cancer were further analyzed. Low levels of miR-137 promoter methylation were significantly associated with smoking, positive lymph node metastasis and advanced clinical stage $(\mathrm{P}=0.027, \mathrm{P}=0.004$ and $\mathrm{P}=0.021$, respectively) (Table II). There was no significant association between miR-137 promoter methylation and sex, age, pathology, tumor size, histological grade or T category (Table II).

High levels of miR-137 promoter methylation are associated with poor disease-free survival. Kaplan-Meier survival 
Table II. Characteristics of 56 patients with non-small cell lung cancer by microRNA-137 promoter methylation levels.

\begin{tabular}{|c|c|c|c|}
\hline Variable & No. & Mean \pm SD & P-value ${ }^{a}$ \\
\hline Sex & & & 0.773 \\
\hline Male & 43 & $49.2 \pm 30.1$ & \\
\hline Female & 13 & $51.8 \pm 25.6$ & \\
\hline Age (years) & & & 0.508 \\
\hline$<60$ & 24 & $46.8 \pm 29.0$ & \\
\hline$\geq 60$ & 32 & $52.0 \pm 29.0$ & \\
\hline Smoking status & & & 0.027 \\
\hline 0 & 18 & $35.8 \pm 21.4$ & \\
\hline$<20$ pack/year & 13 & $50.5 \pm 37.6$ & \\
\hline$\geq 20$ pack-y & 25 & $59.5 \pm 25.2$ & \\
\hline Histiotype & & & 0.643 \\
\hline Adenocarcinoma & 25 & $48.1 \pm 27.6$ & \\
\hline Squamous cell & 31 & $51.8 \pm 30.8$ & \\
\hline T-status & & & 0.610 \\
\hline $\mathrm{T} 1$ & 30 & $46.9 \pm 28.5$ & \\
\hline $\mathrm{T} 2$ & 21 & $51.4 \pm 31.9$ & \\
\hline $\mathrm{T} 3$ & 5 & $60.2 \pm 17.0$ & \\
\hline N-status & & & 0.004 \\
\hline NO & 31 & $38.9 \pm 26.5$ & \\
\hline N1 & 14 & $60.6 \pm 29.9$ & \\
\hline $\mathrm{N} 2$ & 11 & $66.8 \pm 21.5$ & \\
\hline TNM & & & 0.021 \\
\hline I & 26 & $38.8 \pm 28.1$ & \\
\hline II & 17 & $57.8 \pm 27.1$ & \\
\hline III & 13 & $61.7 \pm 26.2$ & \\
\hline Differentiation & & & 0.621 \\
\hline Well & 11 & $50.6 \pm 27.1$ & \\
\hline Moderately & 34 & $51.9 \pm 29.6$ & \\
\hline Poorly & 11 & $42.1 \pm 29.7$ & \\
\hline
\end{tabular}

${ }^{\mathrm{a} A s}$ determined by one-way analysis of variance. SD, standard deviation; T, tumor; N, node; TNM, Tumor-Node-Metastasis; SD, standard deviation; T, tumor; N, node; TNM, Tumor-Node-Metastasis.

analysis and multivariate Cox proportional hazards analysis were employed to evaluate the association between miR-137 promoter methylation and prognosis in NSCLC. In the present study, 1 patient succumbed to pneumonia shortly after surgery and 8 patients were lost to follow-up. Patients were stratified according to the median relative miR-137 promoter methylation level $(43.79 \%)$ in the tumor specimens from the remaining 47 tumor tissues; low miR-137 promoter methylation ( $\mathrm{n}=24$; $\leq$ median) and high miR-137 promoter methylation group ( $\mathrm{n}=23$; >median). In univariate Kaplan-Meier analysis, patients with high levels of miR-137 promoter methylation exhibited significantly poorer disease-free survival rates $(\mathrm{P}=0.034$; Fig. $3 \mathrm{~A})$, but no significant difference was observed in overall survival rates $(\mathrm{P}=0.136$; Fig. $3 \mathrm{~B})$, compared with patients with low levels of miR-137 promoter methylation.
Table III. Cox proportional hazards model analysis of adjusted hazard ratios for progression-free and overall survival rates according to miRNA-137 promoter methylation levels in NSCLC patients.

miR-137 promoter

methylation levels HR $\quad$ 95\% CI P-value

Progression-free survival

Low levels $\quad 1.000$

High levels $\quad 3.333$

$1.108-10.029 \quad 0.032$

$\begin{array}{llll}\text { Sex } & 0.298 & 0.061-1.453 & 0.134\end{array}$

Age

$\begin{array}{lll}1.081 & 0.302-3.866 & 0.904\end{array}$

$\begin{array}{llll}\text { Smoking status } & 1.359 & 0.678-2.726 & 0.387\end{array}$

$\begin{array}{llll}\text { Histiotype } & 2.255 & 0.554-9.172 & 0.256\end{array}$

$\begin{array}{llll}\text { T-stage } & 0.044 & 1.021-4.919 & 0.044\end{array}$

Overall survival

Low levels $\quad 1.000$

High $\quad 2.537 \quad 0.934-6.890 \quad 0.366$

$\begin{array}{llll}\text { Sex } & 0.341 & 0.070-1.655 & 0.182\end{array}$

Age $\quad 1.503 \quad 0.407-5.548 \quad 0.541$

$\begin{array}{llll}\text { Smoking status } & 1.439 & 0.711-2.913 & 0.311\end{array}$

$\begin{array}{llll}\text { Histiotype } & 2.497 & 0.572-10.983 & 0.572\end{array}$

$\begin{array}{llll}\text { T-stage } & 1.554 & 0.781-3.091 & 0.209\end{array}$

NSCLC, non-small cell lung cancer; HR, hazard ratio; CI, confidence interval; $\mathrm{T}$, tumor.

In the multivariable Cox proportional hazards analysis, adjusting for gender, age, histologic grade, smoking status and $\mathrm{T}$ stage, the results showed that patients with high levels of miR-137 promoter methylation had a higher risk of diseasefree death (hazard ratio, 3.333; 95\% CI, 1.108-10.028, $\mathrm{P}=0.032$, Table III) compared with the patients with low levels of miR-137 promoter methylation; levels of miR-137 promoter methylation was not significantly associated with overall survival $(\mathrm{P}=0.366)$.

\section{Discussion}

The aim of the present study was to investigate whether miR-137 promoter hypermethylation is associated with overall survival and disease-free survival in lung cancer. Although miR-137 has been reported to exert tumor-suppressor activity in various types of cancer (12-18), there is limited data on the function of miR-137 in NSCLC. The present study demonstrated that miR-137 is downregulated in NSCLC cell lines and tumor tissues.

Several factors may reduce the expression of miRNAs. DNA methylation of $\mathrm{CpG}$ islands is an important regulatory mechanism for gene expression, which has also been revealed to be responsible for inactivating the expression of miRNAs, including that of miRNA-137 (19). miR-137 is downregulated in the tissues of several types of cancer compared with normal tissues $(11-16,23)$ and functions as a tumor suppressor by targeting several genes, including cyclooxygenase-2, cell division protein kinase 6 , cell division control protein 

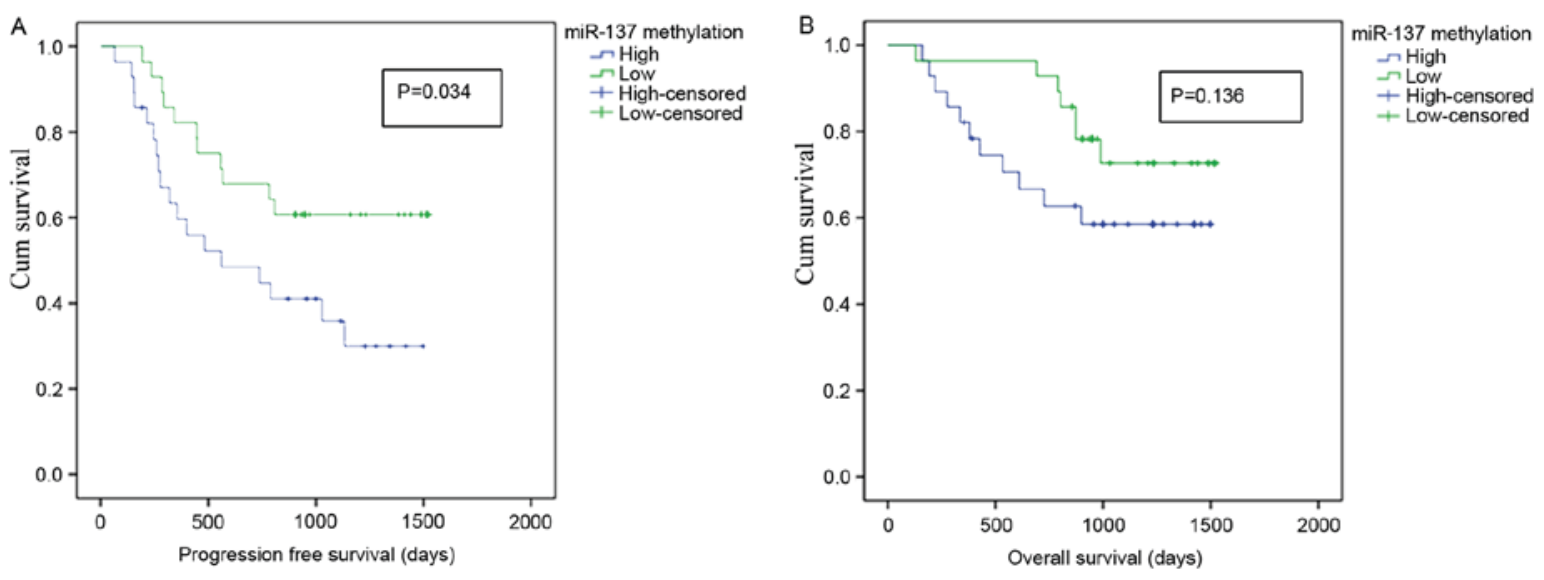

Figure 3. Survival analysis. Kaplan-Meier curves for (A) disease-free survival and (B) overall survival curves for patients with non-small cell lung cancer stratified by the level of miRNA-137 promoter methylation. Survival data were compared using the log-rank test. Patients with low levels of miRNA-137 promoter methylation exhibited shorter disease-free and overall survival times than patients with high levels of miRNA-137 promoter methylation. miRNA, microRNA.

42 homolog, C-terminal-binding protein 1, estrogen-related receptor, KIT proto-oncogene receptor tyrosine kinase, glioma pathogenesis-related protein-1, paxillin and solute carrier family 22 member 8 (12-15,24-29). Treatment with the DNA methytransferase inhibitor 5-aza-dC increased miR-137 expression in A549 and H1299 cells, suggesting that promoter methylation may be one mechanism that leads to the silencing of miR-137 in lung cancer, which is consistent with the study of Kang et al (19). In agreement with this hypothesis, the level of miR-137 promoter methylation was significantly correlated with miR-137 expression in the 56 human lung cancer tissues tested in the present study.

In line with the results of a study undertaken by Zhang et al (12) on non-small-cell lung cancer, low levels of miR-137 promoter methylation were significantly associated with smoking, positive lymph node status and advanced Tumor-Node-Metastasis stage in human NSCLC, but not with tumor size, tumor status, sex, differentiation or histological type. Furthermore, to the best of our knowledge, the present study provides the first evidence that high levels of miR-137 promoter methylation are associated with poor disease-free survival, and multivariate Cox proportional hazards analysis demonstrated that miR-137 promoter methylation was an independent prognostic factor for disease-free survival.

The present study has a number of limitations. To begin with, the role of miR-137 as a tumor-suppressor in lung cancer was not confirmed. Secondly, further research is required to investigate the environmental and personal risk factors associated with miR-137 promoter methylation. Finally, due to the relatively small sample size and short follow-up in the present study, further research is required to confirm the association between miR-137 promoter methylation and survival outcomes in NSCLC.

In conclusion, aberrant miR-137 promoter methylation is a common feature in NSCLC. Further studies should focus on the quantitative assessment of miR-137 promoter methylation in tumor tissues and specific types of lung cancer, with the aim of developing etiological and prognostic markers to prolong survival in lung cancer.

\section{Acknowledgements}

Not applicable.

\section{Funding}

The present study was supported by the National Natural Science Foundation of China (grant nos. 81302016 and 81302015), the National Natural Science Foundation of Jiangsu Province, China (grant nos. BK20130456 and BK20140101) and the Six Talent Peaks Project in Jiangsu, China (grant no. WSN-106).

\section{Availability of data and materials}

The datasets used or analyzed during the present study are available from the corresponding author on reasonable request.

\section{Author's contributions}

Conceptualization, LM, FW and XX. Formal analysis, LM. Funding acquisition, LM and YC. Methodology, SL, YC and JY. Resources, LM and SH. Software, LM and SL. Supervision, XX and SH. Analysis and interpretation of data, SH. Writing-original draft, LM. Writing-review and editing, $\mathrm{XX}$.

\section{Ethics approval and consent to participate}

The present study was approved by the Ethics Committee of Subei People's Hospital (Yangzhou, China) and written informed consent was obtained from all participants.

\section{Consent for publication}

Written informed consent was obtained from all participants.

\section{Competing interests}

The authors declare that they have no competing interests. 


\section{References}

1. Jemal A, Bray F, Center MM, Ferlay J, Ward E and Forman D: Global cancer statistics. CA Cancer J Clin 61: 69-90, 2011.

2. Reck M, Popat S, Reinmuth N, De Ruysscher D, Kerr KM and Peters S; ESMO Guidelines Working Group: Metastatic non-small-cell lung cancer (NSCLC): ESMO clinical practice guidelines for diagnosis, treatment and follow-up. Ann Oncol 25 (Suppl 3): iii27-iii39, 2014.

3. Field JK, Oudkerk M, Pedersen JH and Duffy SW: Prospects for population screening and diagnosis of lung cancer. Lancet 382 732-741, 2013.

4. Minna JD, Roth JA and Gazdar AF: Focus on lung cancer. Cancer Cell 1: 49-52, 2002.

5. Bartel DP: MicroRNAs: Genomics, biogenesis, mechanism and function. Cell 116: 281-297, 2004.

6. Calin GA and Croce CM: MicroRNA signatures in human cancers. Nat Rev Cancer 6: 857-866, 2006.

7. Lu J, Getz G, Miska EA, Alvarez-Saavedra E, Lamb J, Peck D, Sweet-Cordero A, Ebert BL, Mak RH, Ferrando AA, et al: MicroRNA expression profiles classify human cancers. Nature 435 834-838, 2005.

8. Garzon R, Calin GA and Croce CM: MicroRNAs in cancer. Annu Rev Med 60: 167-179, 2009.

9. Han L, Witmer PD, Casey E, Valle D and Sukumar S: DNA methylation regulates MicroRNA expression. Cancer Biol Ther 6: 1284-1288, 2007.

10. Kozaki K, Imoto I, Mogi S, Omura K and Inazawa J: Exploration of tumor-suppressive microRNAs silenced by DNA hypermethylation in oral cancer. Cancer Res 68: 2094-2105, 2008.

11. Silber J, Lim DA, Petritsch C, Persson AI, Maunakea AK, Yu M, Vandenberg SR, Ginzinger DG, James CD, Costello JF, et al: miR-124 and miR-137 inhibit proliferation of glioblastoma multiforme cells and induce differentiation of brain tumor stem cells. BMC Med 6: 14, 2008.

12. Zhang B, Liu T, Wu T, Wang Z, Rao Z and Gao J: microRNA-137 functions as a tumor suppressor in human non-small cell lung cancer by targeting SLC22A18. Int J Biol Macromol 74: 111-118, 2015.

13. Bier A, Giladi N, Kronfeld N, Lee HK, Cazacu S, Finniss S, Xiang C, Poisson L, deCarvalho AC, Slavin S, et al: MicroRNA-137 is downregulated in glioblastoma and inhibits the stemness of glioma stem cells by targeting RTVP-1. Oncotarget 4: 665-676, 2013.

14. Chen L, Wang X, Wang H, Li Y, Yan W, Han L, Zhang K, Zhang J, Wang Y, Feng Y, et al: miR-137 is frequently down-regulated in glioblastoma and is a negative regulator of Cox-2. Eur J Cancer 48: 3104-3111, 2012.

15. Chen Q, Chen X, Zhang M, Fan Q, Luo S and Cao X: miR-137 is frequently down-regulated in gastric cancer and is a negative regulator of Cdc42. Dig Dis Sci 56: 2009-2016, 2011.

16. Balaguer F, Link A, Lozano JJ, Cuatrecasas M, Nagasaka T, Boland CR and Goel A: Epigenetic silencing of miR-137 is an early event in colorectal carcinogenesis. Cancer Res 70: 6609-6618, 2010.

17. Steponaitiene R, Kupcinskas J, Langner C, Balaguer F, Venclauskas L, Pauzas H, Tamelis A, Skieceviciene J, Kupcinskas L, Malfertheiner P and Link A: Epigenetic silencing of miR-137 is a frequent event in gastric carcinogenesis. Mol Carcinog 55: 376-386, 2015.

18. Langevin SM, Stone RA, Bunker CH, Lyons-Weiler MA, LaFramboise WA, Kelly L, Seethala RR, Grandis JR, Sobol RW and Taioli E: MicroRNA-137 promoter methylation is associated with poorer overall survival in patients with squamous cell carcinoma of the head and neck. Cancer 117 1454-1462, 2011.
19. Kang N, Choi SY, Kim YK, Yoo IeR, Han DH, Lee DS, Kim YS, Hong SH, Kang JH, Lee KY, et al: Silencing of miR-137 by aberrant promoter hypermethylation in surgically resected lung cancer. Lung Cancer 89: 99-103, 2015.

20. Reddel RR, Ke Y, Gerwin BI, McMenamin MG, Lechner JF, Su RT, Brash DE, Park JB, Rhim JS and Harris CC: Transformation of human bronchial epithelial cells by infection with SV40 or adenovirus-12 SV40 hybrid virus, or transfection via strontium phosphate coprecipitation with a plasmid containing SV40 early region genes. Cancer Res 48: 1904-1909, 1988.

21. Livak KJ and Schmittgen TD: Analysis of relative gene expression data using real-time quantitative PCR and the 2(-Delta Delta C(T)) method. Methods 25: 402-408, 2001.

22. Shepherd FA, Crowley J, Van Houtte P, Postmus PE, Carney D, Chansky K, Shaikh Z and Goldstraw P; International Association for the Study of Lung Cancer International Staging Committee and Participating Institutions: The international association for the study of lung cancer lung cancer staging project: Proposals regarding the clinical staging of small cell lung cancer in the forthcoming (seventh) edition of the tumor, node, metastasis classification for lung cancer. J Thorac Oncol 2: 1067-1077, 2007.

23. Dacic S, Kelly L, Shuai Y and Nikiforova MN: miRNA expression profiling of lung adenocarcinomas: Correlation with mutational status. Mod Pathol 23: 1577-1582, 2010

24. Bemis LT, Chen R, Amato CM, Classen EH, Robinson SE, Coffey DG, Erickson PF, Shellman YG and Robinson WA: MicroRNA-137 targets microphthalmia-associated transcription factor in melanoma cell lines. Cancer Res 68: 1362-1368, 2008.

25. Deng Y, Deng H, Bi F, Liu J, Bemis LT, Norris D, Wang XJ and Zhang Q: MicroRNA-137 targets carboxyl-terminal binding protein 1 in melanoma cell lines. Int J Biol Sci 7: 133-137, 2011.

26. Zhao Y, Li Y, Lou G, Zhao L, Xu Z, Zhang Y and He F: miR-137 targets estrogen-related receptor alpha and impairs the proliferative and migratory capacity of breast cancer cells. PLoS One 7: e39102, 2012.

27. Zhu X, Li Y, Shen H, Li H, Long L, Hui L and Xu W: miR-137 inhibits the proliferation of lung cancer cells by targeting Cdc42 and Cdk6. FEBS Lett 587: 73-81, 2013.

28. Bi Y, Han Y, Bi H, Gao F and Wang X: miR-137 impairs the proliferative and migratory capacity of human non-small cell lung cancer cells by targeting paxillin. Hum Cell 27: 95-102, 2014.

29. Li P, Ma L, Zhang Y, Ji F and Jin F: MicroRNA-137 down-regulates KIT and inhibits small cell lung cancer cell proliferation. Biomed Pharmacother 68: 7-12, 2014.

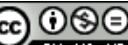

This work is licensed under a Creative Commons Attribution-NonCommercial-NoDerivatives 4.0 International (CC BY-NC-ND 4.0) License. 